\title{
Genetic Divergence Studies for Yield and Quality Traits in Onion (Allium cepa L.)
}

\author{
Solanki Bal $^{1 *}$, Tapan Kumar Maity ${ }^{1}$ and Anirban Maji ${ }^{2}$ \\ ${ }^{1}$ Department of Vegetable Science, ${ }^{2}$ Department of Genetics and Plant Breeding, Bidhan \\ Chandra Krishi Viswavidyalaya, Mohanpur, Nadia, West Bengal, India
}

*Corresponding author

\begin{tabular}{l} 
K e y w o r d s \\
$\begin{array}{l}\text { Onion, Genetic } \\
\text { divergence, Cluster } \\
\text { analysis, Yield, } \\
\text { Quality }\end{array}$ \\
Article Info \\
$\begin{array}{l}\text { Accepted: } \\
\text { 21 May } 2020 \\
\text { Available Online: } \\
\text { 10 June } 2020\end{array}$ \\
\hline
\end{tabular}

\section{A B S T R A C T}

Genetic divergence study, using Mahalanobis $\mathrm{D}^{2}$ statistics, was conducted in twenty-three onion genotypes for fourteen characters. Among the characters studied; total yield, phenol, pyruvic acid, vitamin $\mathrm{C}$ content contributed maximum towards divergence. The maximum number of genotypes was grouped into cluster VI while the minimum was in cluster VIII. The intra-cluster distance varied from 0.00 (cluster VIII) to 14.618 (cluster IV). The maximum inter-cluster distance (32.763) was found between cluster V and VIII, indicating that hybridization can be taken up between the genotypes of these two clusters for obtaining superior recombinants or transgressive segregants. The genotype of cluster VIII showed superior performance for the plant height at $60 \mathrm{DAT}$, polar and equatorial diameter, number of scales per bulb, total sugar and dry matter percentage, TSS, vitamin $\mathrm{C}$, phenol and pyruvic acid content and total yield. The genotypes of cluster III were found to be superior for the number of days to maturity. Thus, based on the diversity pattern and mean performances, the genotypes viz., Sukhsagar from cluster VIII; Arka Bheem and Arka Niketan from cluster VI; Bhima Raj from cluster II and HO-3 from cluster V would be the best choice as parents for future hybridization programs.

\section{Introduction}

Onion (Allium cepa L.) is one of the most important vegetables cum spice crops throughout the globe. It is commercially grown in temperate, sub-tropical as well as in tropical regions throughout the world (Brewster, 1990; Corgan and Kedar, 1990;
Currah and Proctor, 1990). Onion had its primary centre of origin in Southwest Asian gene centre, whereas, the Mediterranean gene centre is regarded as its secondary centre of origin (Vavilov, 1926). In India, majority of the harvest is obtained from winter (rabi) season. Onion is purely photosensitive and, on this basis, varieties are precisely classified 
into short- and long-day types. Short day types generally have low yielding potential but have better shelf life whereas long day types have high yield potential with poor shelf life. The severity of purple blotch (caused by Alternaria porri) and Stemphylium blight (caused by Stemphylium vesicarium) disease shutters down the productivity during rabi season (Bal et al., 2019). Despite its global importance, there is a sharp lacuna in genetic improvement of onion when compared to other vegetable crops (McCallum et al., 2008). This may probably be due to lack of proper evaluation and data classification for various parameters including yield. Moreover, under Indian conditions, it is very challenging to breed short-day onion varieties for high yield potential coupled with resistance to different biotic and abiotic stresses. So, for success in any genetic improvement programme involving hybridization, selection of genetically diverse parents is of utmost importance (Arunachalam, 1981; Singh et al., 2013; Rivera et al., 2016). Moreover, genetic diversity studies provide an insight into the genetic distance among the accessions and thus increases the probability of obtaining transgressive segregants in $\mathrm{F}_{2}$ and subsequent generations (Pal et al., 2017). Keeping these facts in mind, the present study was attempted to estimate the genetic divergence for different morphological, yield and quality traits in twenty-three genotypes through Mahalanobis $\mathrm{D}^{2}$ analysis.

\section{Materials and Methods}

The present experiment was conducted at ' $\mathrm{C}$ ' Block Farm of Bidhan Chandra Krishi Viswavidyalaya, Kalyani, Nadia, West Bengal. The experimental plot is located at $23.50^{\circ} \mathrm{N}$ latitude and $89^{\circ} \mathrm{E}$ longitude at a mean sea level of $9.75 \mathrm{~m}$. The soil of the experimental farm was fine sandy-loam in texture, neutral in reaction with good water holding capacity. The meteorological observations taken during the experimental period of 2017-18 and 2018-19 have been presented in Figures 1 and 2.

The experimental material was comprised of twenty-three onion genotypes collected from different states of the country (Table 1). The experiment was laid out in Randomized Complete Block Design with three replications. The seeds were sown in the nursery beds to raise the seedlings. Subsequently, 50 days old seedlings were transplanted in the main field during the rabi season of 2017-18 and 2018-19. A spacing of $15 \times 10 \mathrm{~cm}$ was followed between rows and plants, respectively, in a plot size of $2 \mathrm{~m} \times 1$ $\mathrm{m}$, accommodating 133 plants per plot. The standard package of practices was followed thereafter to raise a healthy crop. The observations were recorded for plant height and number of leaves at 60 days after transplanting (DAT; cm), days to maturity, equatorial and polar diameter ( $\mathrm{mm})$, average weight of ten bulbs $(\mathrm{kg})$, number of scales per bulb, total sugar and dry matter percentage, TSS ( ${ }^{\circ}$ Brix), vitamin C (mg/g), phenol $(\mathrm{mg} / \mathrm{g})$, pyruvic acid ( $\mu$ mole/g) and total yield (kg/plot). The data were analyzed using SPAR 1.0 software packages.

\section{Results and Discussion}

To estimate the genetic distance among different genotypes for fourteen different traits, the genetic divergence with clustering pattern was worked out in the present study. The analysis of variance inferred highly significant differences among the genotypes for all the characters under study, indicating the existence of ample genetic divergence among them. Information on genetic diversity was also used to identify promising diverse genotypes, which may further be used in breeding programmes.

Analysis based on $\mathrm{D}^{2}$ statistics revealed that the total yield per plot contributed maximum towards divergence i.e., 57.312\% (Table 2). 
Meheta et al. (2008) also reported that the gross and marketable yield were major contributors towards genetic divergence in onion. The traits viz., phenol (27.272), pyruvic acid (6.719), vitamin C (6.324) content, number of days to maturity $(0.791)$, TSS (0.400), dry matter percentage (0.400), number of scales per bulb (0.400), average weight of 10 bulbs (0.400) cumulatively contributed to $42.70 \%$ of the total divergence. The contribution of plant height and number of leaves at 60 DAT, equatorial diameter, total sugar content was found to be negligible.

Based on their genetic divergence, clustering pattern of twenty-three onion genotypes have been presented in Table 3. All the genotypes were grouped into eight clusters. The maximum number of genotypes had entered into cluster $\mathrm{VI}(\mathrm{n}=5)$ followed by cluster I $(n=4)$, cluster IV $(n=4)$, cluster V $(n=3)$, cluster II $(n=2)$, cluster III $(n=2)$ cluster VII $(n=2)$ and cluster VIII $(n=1)$. It was also evident from the grouping pattern that the genotypes collected from the same geographical area were clustered into different clusters, indicating that the genetic diversity is independent of the place of collection which might have resulted from the frequent exchange of germplasm between different geographical regions.

Table.1 List of the genotypes and along with their sources

\begin{tabular}{|c|c|c|}
\hline Sl. & Name of the genotype & Sources \\
$\mathbf{N o .}$ & & \\
\hline $\mathbf{1}$ & Arka Bheem & ICAR-IIHR, Bangalore \\
\hline $\mathbf{2}$ & Arka Kirtiman & ICAR-IIHR, Bangalore \\
\hline $\mathbf{3}$ & Arka Lalima & ICAR-IIHR, Bangalore \\
\hline $\mathbf{4}$ & Arka Niketan & ICAR-IIHR, Bangalore \\
\hline $\mathbf{5}$ & Akola Safed & PDKV, Akola, Maharashtra \\
\hline $\mathbf{6}$ & Agrifound Light Red & NHRDF, Nasik, Maharashtra \\
\hline $\mathbf{7}$ & Bhima Dark Red & DOGR, Rajgurunagar \\
\hline $\mathbf{8}$ & Bhima Kiran & DOGR, Rajgurunagar \\
\hline $\mathbf{9}$ & Bhima Raj & DOGR, Rajgurunagar \\
\hline $\mathbf{1 0}$ & Bhima Red & DOGR, Rajgurunagar \\
\hline $\mathbf{1 1}$ & Bhima Safed & DOGR, Rajgurunagar \\
\hline $\mathbf{1 2}$ & Bhima Shakti & DOGR, Rajgurunagar \\
\hline $\mathbf{1 3}$ & Bhima Subhra & DOGR, Rajgurunagar \\
\hline $\mathbf{1 4}$ & Bhima Super & DOGR, Rajgurunagar \\
\hline $\mathbf{1 5}$ & Bhima Sweta & DOGR, Rajgurunagar \\
\hline $\mathbf{1 6}$ & Hisar-2 & HAU, Hisar \\
\hline $\mathbf{1 7}$ & Hisar-4 & HAU, Hisar \\
\hline $\mathbf{1 8}$ & Kalyanpur Red Round & CSAUAT, Kanpur \\
\hline $\mathbf{1 9}$ & L-28 & NHRDF, Nasik, Maharashtra \\
\hline $\mathbf{2 0}$ & Onion HO-3 & PAU,Ludhiana, Punjab \\
\hline $\mathbf{2 1}$ & PRO-6 & PAU,Ludhiana, Punjab \\
\hline $\mathbf{2 2}$ & Punjab Naroya & \\
\hline $\mathbf{2 3}$ & Sukhsagar & \\
\hline & & \\
\hline
\end{tabular}


Table. 2 Contribution of fourteen morphometric, yield-contributing and quality traits genetic divergence

\begin{tabular}{|c|c|c|}
\hline Sl. No. & Characters & Contribution towards genetic divergence (\%) \\
\hline $\mathbf{1}$ & Plant height at 60DAT $(\mathrm{cm})$ & 0.000 \\
\hline $\mathbf{2}$ & Number of leaves at 60 DAT & 0.000 \\
\hline $\mathbf{3}$ & Number of days to maturity & 0.791 \\
\hline $\mathbf{4}$ & Polar diameter(mm) & 0.000 \\
\hline $\mathbf{5}$ & Equatorial diameter $(\mathrm{mm})$ & 0.000 \\
\hline $\mathbf{6}$ & Average weight of 10 bulbs $(\mathrm{kg})$ & 0.400 \\
\hline $\mathbf{7}$ & Number of scales per bulb & 0.400 \\
\hline $\mathbf{8}$ & Total sugar $(\%)$ & 0.000 \\
\hline $\mathbf{9}$ & Dry matter $(\%)$ & 0.400 \\
\hline $\mathbf{1 0}$ & TSS $\left({ }^{\circ} \mathrm{Brix}\right)$ & 0.400 \\
\hline $\mathbf{1 1}$ & Vitamin C $(\mathrm{mg} / \mathrm{g})$ & 6.324 \\
\hline $\mathbf{1 2}$ & Phenol $(\mathrm{mg} / \mathrm{g})$ & 27.272 \\
\hline $\mathbf{1 3}$ & Pyruvic acid $(\mu \mathrm{mole} / \mathrm{g})$ & 6.719 \\
\hline $\mathbf{1 4}$ & Total yield $(\mathrm{kg} / \mathrm{plot})$ & 57.312 \\
\hline & Total & 100 \\
\hline
\end{tabular}

Table.3 Clustering pattern of twenty-three onion genotypes based on genetic divergence

\begin{tabular}{|c|c|l|}
\hline Cluster & Number of genotypes & Name of genotypes \\
\hline I & 4 & Bhima Sweta, Hisar 4,L-28, Bhima Subhra \\
\hline II & 2 & Bhima Raj, Hisar 2 \\
\hline III & 2 & PRO-6, Arka Lalima \\
\hline IV & 4 & Punjab Naroya, Bhima Dark Red, Kalyanpur Red Round, Bhima Red \\
\hline V & 3 & Bhima Super, Bhima Safed, Onion HO-3 \\
\hline VI & 5 & Akola Safed, Agrifound Light Red, Arka Bheem, Arka Kirtiman, Arka Niketan \\
\hline VII & 2 & Bhima Shakti, Bhima Kiran \\
\hline VIII & 1 & Sukhsagar \\
\hline
\end{tabular}

Table.4 Average intra- (Diagonal and underlined) and inter-cluster (Upper half Diagonal) distance

\begin{tabular}{|c|c|c|c|c|c|c|c|c|}
\hline Clusters & I & II & III & IV & V & VI & VII & VIII \\
\hline I & $\underline{\mathbf{9 . 7 9 1}}$ & 10.939 & 9.433 & 22.068 & 9.007 & 20.153 & 11.917 & 30.294 \\
\hline II & & $\underline{\mathbf{5 . 0 9 5}}$ & 8.934 & 16.768 & 12.977 & 14.774 & 7.965 & 22.528 \\
\hline III & & & $\underline{\mathbf{5 . 4 6 2}}$ & 16.974 & 10.345 & 15.188 & 11.124 & 25.946 \\
\hline IV & & & & $\underline{\mathbf{1 4 . 6 1 8}}$ & 24.460 & 12.774 & 19.993 & 18.441 \\
\hline $\mathbf{V}$ & & & & & $\underline{\mathbf{8 . 7 0 8}}$ & 22.464 & 13.304 & 32.763 \\
\hline VI & & & & & & $\underline{\mathbf{1 2 . 4 0 7}}$ & 17.697 & 17.036 \\
\hline VII & & & & & & & $\underline{\mathbf{1 2 . 2 9 6}}$ & 24.437 \\
\hline VIII & & & & & & & & $\underline{\mathbf{0 . 0 0 0}}$ \\
\hline
\end{tabular}


Table.5 Cluster means for different characters among twenty-three genotypes of onion

\begin{tabular}{|c|c|c|c|c|c|c|c|c|}
\hline Characters & I & II & III & IV & $\mathbf{V}$ & VI & VII & VIII \\
\hline $\begin{array}{c}\text { Plant height at } \\
\text { 60DAT }(\mathrm{cm})\end{array}$ & 53.06 & 48.55 & 51.33 & 51.70 & 51.87 & 50.78 & 51.35 & 59.96 \\
\hline $\begin{array}{c}\text { Number of leaves at } \\
\text { 60DAT }\end{array}$ & 5.36 & 5.36 & 5.000 & 4.90 & 5.13 & 5.30 & 5.56 & 6.06 \\
\hline Days to maturity & 131.16 & 130.33 & 133.50 & 132.58 & 130.11 & 133.06 & 131.50 & 132.00 \\
\hline Polar diameter (mm) & 51.20 & 48.06 & 55.08 & 55.31 & 53.24 & 52.31 & 51.79 & 58.50 \\
\hline Equatorial diameter (mm) & 50.24 & 52.61 & 46.73 & 50.37 & 47.00 & 49.78 & 53.74 & 56.95 \\
\hline $\begin{array}{c}\text { Average weight of } 10 \\
\text { bulbs (kg) }\end{array}$ & 0.57 & 0.54 & 0.53 & 0.57 & 0.46 & 0.54 & 0.67 & 0.62 \\
\hline Number of scales/bulb & 7.08 & 6.77 & 7.54 & 7.52 & 7.07 & 9.33 & 6.83 & 10.33 \\
\hline Total sugar\% & 1.96 & 1.22 & 1.59 & 1.33 & 1.48 & 1.76 & 2.17 & 3.48 \\
\hline Dry matter\% & 4.65 & 4.76 & 12.93 & 8.26 & 12.88 & 14.63 & 20.08 & 32.33 \\
\hline TSS $\left({ }^{0}\right.$ Brix $)$ & 8.39 & 8.42 & 7.72 & 8.79 & 7.15 & 12.06 & 10.20 & 14.29 \\
\hline Vitamin C (mg/g) & 0.24 & 0.48 & 0.25 & 0.34 & 0.24 & 0.37 & 0.48 & 0.71 \\
\hline Phenol (mg/g) & 3.14 & 4.55 & 4.25 & 7.10 & 2.78 & 6.44 & 3.83 & 8.20 \\
\hline Pyruvic acid ( $\mu$ mole/g) & 1.30 & 1.49 & 1.68 & 1.13 & 1.37 & 1.36 & 1.99 & 3.16 \\
\hline Total yield(kg/plot) & 2.86 & 2.83 & 2.41 & 2.45 & 1.98 & 2.71 & 3.67 & 5.25 \\
\hline
\end{tabular}

Figure.1 Meteorological observations during the experimental period of 2017-18

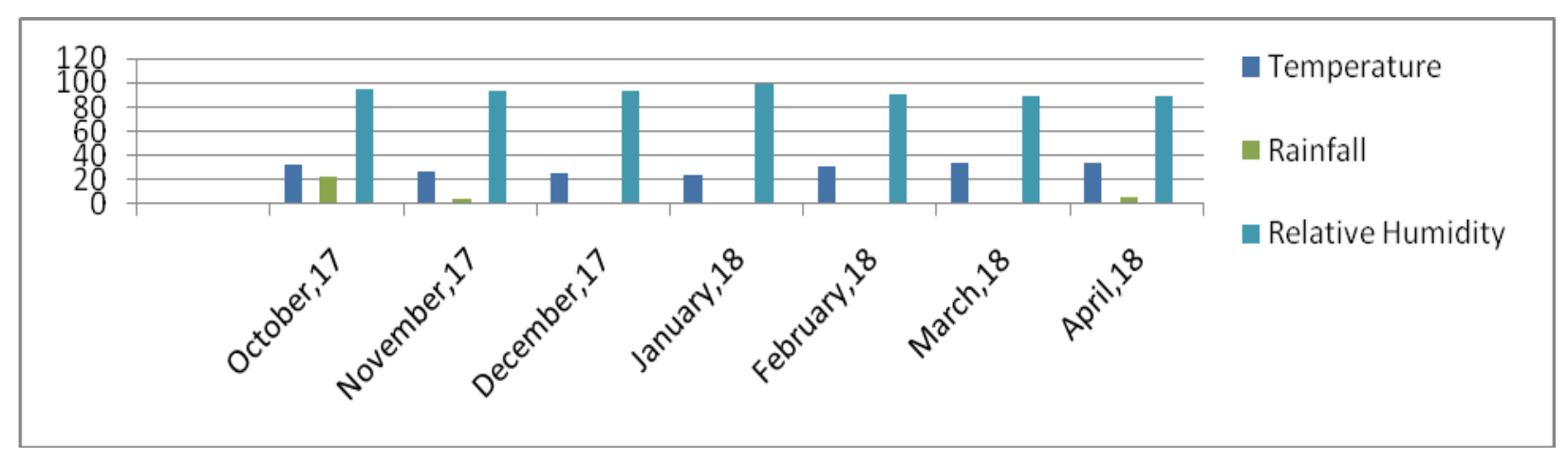

Figure.2 Meteorological observations during the experimental period of 2018-19

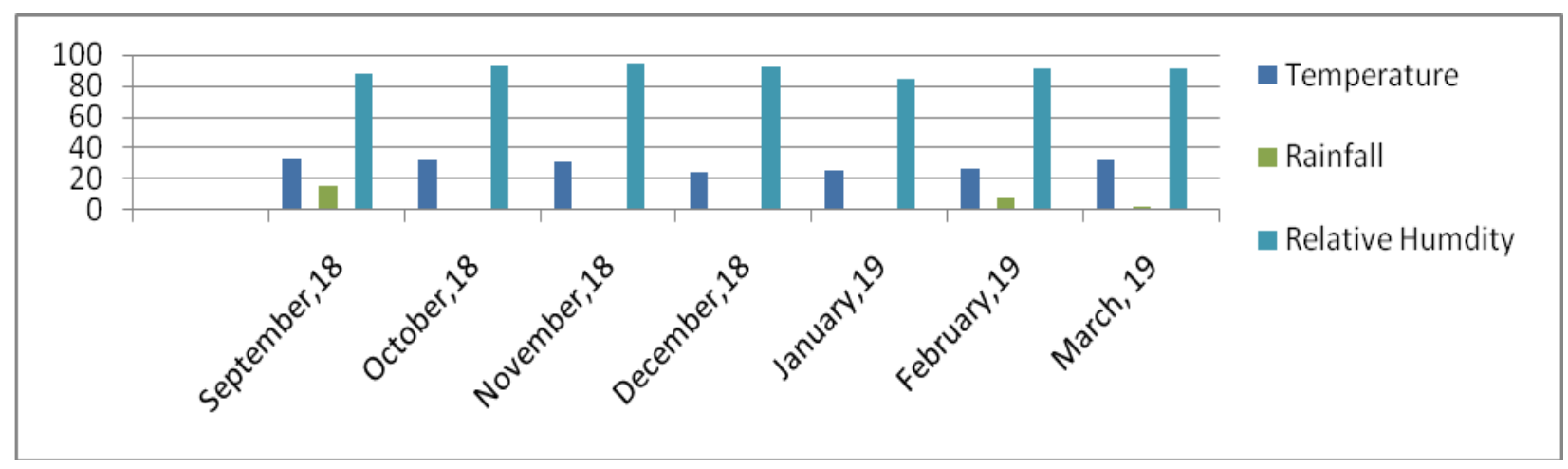


Figure.3 Representation of genetic divergence in onion genotypes through the dendrogram

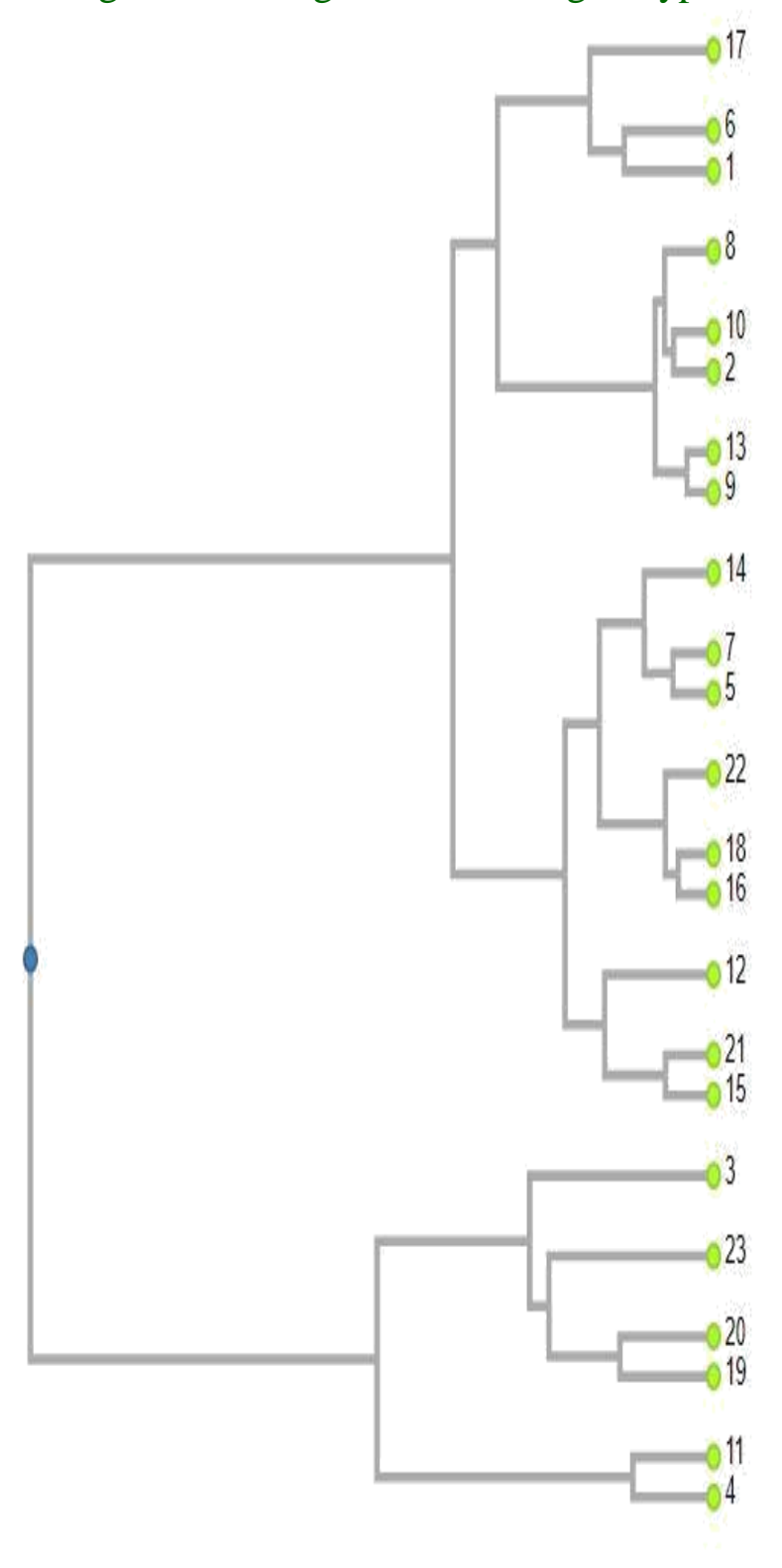

Where,

1-Bhima Sweta, 2-Hisar-4, 3-Punjab Naroya, 4-Bhima Dark Red, 5-PRO-6, 6-Bhima Super, 7-Arka Lalima, 8Bhima Safed, 9-L-28, 10-Onion HO-3, 11-Akola Safed, 12-Agrifound Light Red, 13-Bhima Subhra, 14-Arka Bheem, 15-Kalyanpur Red Round, 16-Bhima Raj, 17-Bhima Shakti, 18-Hisar-2, 19-Arka Kirtiman, 20-Arka Niketan, 21-Bhima Red, 22-Bhima Kiran, 23-Sukhsagar

The average inter-cluster and intra-cluster distance $\left(\mathrm{D}^{2}\right)$ values have been presented in Table 4. The diagonal figures in the table represent the intra-cluster distance (Fig. 3). The intra-cluster distance varied from cluster VIII (0.000) to cluster IV (14.618). The minimum intra-cluster distance in cluster VIII was due to the presence of only a single genotype in that. The maximum inter-cluster distance (32.763) was found between cluster $\mathrm{V}$ and VIII. This indicates that hybridization can be taken up between the genotypes 
belonging to these two clusters for obtaining superior recombinants or transgressive segregants. Further, the inter-cluster distance between cluster V and VIII was followed by cluster I and VIII (30.924), cluster III and VIII (25.946), cluster IV and V (24.460), cluster VII and VIII (24.437). The minimum inter-cluster distance (7.965) was recorded between cluster II and VII, indicating the genetic relatedness of the genotypes grouped into these two clusters. Therefore, breeding schemes involving hybridization should be avoided between the members of cluster II and VII.

The cluster means of different traits under study have been presented in Table 5. The genotypes of cluster VIII showed superior performances for the plant height at 60 DAT $(59.96 \mathrm{~cm})$, polar $(58.50 \mathrm{~cm})$ and equatorial diameter $(56.95 \mathrm{~cm})$, number of scales per bulb (10.33), total sugar percentage (3.48), dry matter percentage (32.33), TSS (14.29 $\left.{ }^{\circ} \mathrm{B}\right)$, vitamin $\mathrm{C}(0.71 \mathrm{mg} / \mathrm{g})$, phenol $(8.20$ $\mathrm{mg} / \mathrm{g})$, pyruvic acid (3.16 $\mu$ mole/g) content and total yield per plot $(5.25 \mathrm{~kg})$. The genotypes of cluster III outperformed for the number of days to maturity (133.50).

Based on the diversity pattern and mean performances of the genotypes under study, it is concluded that the genotypes Sukhsagar from cluster VIII; Arka Bheem and Arka Niketan from cluster VI; Bhima Raj from cluster II and HO-3 from cluster V would be the best choice as parents for future hybridization programs for improving different morphometric, yield and quality traits in onion.

\section{Acknowledgement}

The authors are thankful to Department of Vegetable Science, Faculty of Horticulture, Bidhan Chandra Krishi Viswavidyalaya, for providing all the necessary facilities as well as unstinted help during research work.

\section{References}

Arunachalam, G. 1981. Genetic distances in plant breeding. Indian $J$. Genet.41:226-236.

Bal, S., Maity, T.K., Sharangi, A.B. and Maji A. 2019. Screening of onion (Allium cepa L.) germplasm against purple blotch disease. Journal of Pharmacognosy and Phytochemistry. 8(6): 546-548.

Brewster J. L. 1990. Cultural system and agronomic practices in temperate climates. In: Onion and Allied Crops II: $1-31$.

Corgan J.N, Kedar N. 1990. Onion in tropical climate. In: Onion and Allied Crops II: 31-37.

Currah I, Proctor F.J. 1990. Onion in tropical region. National Research Institute Kent UK. Bulletin. 35:20.

McCallum J., Havey M.J., Shigyo M., Mcmanus M.T., 2008. Molecular approaches to characterizing and improving bulb composition in onion. Acta Hortic. 770:147-151.

Mehta, D. R., Dhaduk, L. K. and Kalathia, K. V. 2005. Genetic variability, diversity correlations and path coefficient analysis of Indian cultivars of onion under Saurashtra region of Gujarat. Recent advances in Allium Research, Proceeding of First National Conference on Alliums, held at Department of Mycology and Plant Pathology, Institute of Agricultural Science Banaras Hindu University, Varanasi, pp. 128-142.

Pal S., Sharma H.R. and Rai A.K. 2017. Estimation of genetic divergence for yield and quality traits in cucumber (Cucumis sativus L.). Green Farming. 8(2): 296-300.

Rivera A, Mallor C, Garcés-Claver A, GarcíaUlloa A, Pomar F and Silvar C. 2016. Assessing the genetic diversity in 
onion (Allium cepa L.) landraces from northwest Spain and comparison with the European variability. New Zealand Journal of Crop and Horticultural Science. 44(2): 103-20.

Singh S R, Ahmed N, Lal S, Ganie S A, Amin M, Jan N and Amin A. 2013. Determination of genetic diversity in onion (Allium cepa L.) by multivariate analysis under long day conditions. African Journal of Agricultural Research. 8(45): 5599-606.

Vavilov N.I., 1926. Origin and geography of cultivated plants. English translation by D Love 1992. Cambridge Univ. Press, Cambridge, UK.

\section{How to cite this article:}

Solanki Bal, Tapan Kumar Maity and Anirban Maji. 2020. Genetic Divergence Studies for Yield and Quality Traits in Onion (Allium cepa L.). Int.J.Curr.Microbiol.App.Sci. 9(06): 32013208. doi: https://doi.org/10.20546/ijcmas.2020.906.383 